\title{
ОРИГИНАЛЬНОЕ ИССЛЕДОВАНИЕ
}

УДК 612.821.6+615.214+591.18

\section{ВЛИЯНИЕ ДИАЗЕПАМА, ПИРАЦЕТАМА И МЕКСИДОЛА НА УСЛОВНЫЙ РЕФЛЕКС ПАССИВНОГО ИЗБЕГАНИЯ}

\author{
А.Н. Иноземцев ${ }^{1,}{ }^{*}$, Д. С. Бережной ${ }^{1,2}$, А.В. Новоселецкая ${ }^{1}$ \\ ${ }^{1}$ Кафедра высшей нервной деятельности, биологический факультет, Московский государствен- \\ ный университет имени М.В. Ломоносова, Россия, 119234, г. Москва, \\ Ленинские горы, д. 1, стр. 12; \\ ${ }^{2}$ Лаборатория клинической и экспериментальной нейрохимии, Научный центр неврологии, Рос- \\ сия, 125367, г. Москва, Волоколамское шоссе, д. 80 \\ "e-mail: a_inozemtsev@mail.ru
}

\begin{abstract}
В опытах на крысах сопоставлено влияние анксиолитика диазепама и ноотропов пирацетама и мексидола на условный рефлекс пассивного избегания (УРПИ) в трехкамерной установке, состоящей из центрального освещенного отсека, темного опасного отсека, в котором крыса получала удар током, и темного безопасного отсека, в котором она не подвергалась электроболевому воздействию. Удар током при выработке УРПИ вызвал у контрольных животных резкое увеличение латентного периода ухода из центрального отсека при тестировании, но при этом не привёл к выбору безопасного отсека. На основе этих данных о различном воздействии удара на УРПИ было сформулировано предположение о том, что процессы обучения, которые обусловливают задержку двигательной реакции и выбор безопасного отсека, имеют различную ассоциативную природу. Увеличение латентного периода связано с классическим условнорефлекторным страхом безотносительно к месту воздействия удара током. Выбор безопасного отсека, напротив, связан с формированием следа памяти о местоположении электрокожного раздражения. Использование фармакологических веществ, по-разному влияющих на страх и память, дало дополнительные аргументы в пользу предположения о различных ассоциативных процессах, определяющих формирование УРПИ. Снижение уровня страха с помощью диазепама уменьшило латентный период двигательной реакции относительно контрольной величины, но не повлияло на выбор безопасного отсека. В отличие от этого, мнемотропные свойства пирацетама и мексидола увеличили предпочтение безопасного отсека без увеличения латентного периода. Эти дифференцированные фармакологические эффекты подтверждают, что УРПИ основан на формировании условной реакции страха, которая вызывает увеличение латентного периода ухода из центрального отсека, и памяти о месте электроболевого воздействия, которая обеспечивает выбор безопасного отсека.
\end{abstract}

Ключевые слова: модифицированное пассивное избегание, память, диазепам, пирацетам, мексидол, условнорефлекторный страх, выбор безопасного отсека

Условный рефлекс пассивного избегания (УРПИ) широко используется для изучения влияния на обучение и память различных факторов. В частности, методика в экспериментальной психофармакологии используется в качестве базисной модели для анализа вновь синтезированных ноотропных веществ, что обусловлено ее достоинствами, такими как быстрота обучения и возможность дифференцированного влияния на различные фазы памяти, не отягощенной последующим обучением. В основном используется камера из темного и освещенного отсеков, соединенных дверцей. Помещенное в освещен- ный отсек животное в силу норкового рефлекса быстро переходит в темный отсек, где получает удар током. Это приводит к резкому увеличению латентного периода (ЛП) захода в него при последующем тестировании, что рассматривается как показатель обучения и памяти.

Работ, посвященных анализу природы следа памяти, формируемого при выработке УРПИ, остается критически мало, несмотря на важность этой проблемы. В основном исходят из постулата, согласно которому след памяти содержит характеристики места нанесения болевого раздражения и обеспечивает "предвосхищение опасных 
последствий входа в него" [1]. Для анализа этого постулата было изучено формирование УРПИ в трехкамерной установке, состоящей из освещенного отсека, темного опасного отсека, в котором крыса получала удар током, и темного безопасного отсека, в котором она не подвергалась электроболевому воздействию [2]. Предполагалось, что если постулат верен, то животные будут заходить в безопасный отсек.

Однако было установлено, что увеличение ЛП реакции не приводит к выбору безопасного отсека не только при однократном, но даже и при трехкратном обучении (ударах током в опасном отсеке при заходе в него в последовательных тестированиях). На этом основании было высказано предположение, что процессы обучения, которые вызывают увеличение ЛП и выбор безопасного отсека, имеют различную ассоциативную природу. Увеличение времени пребывания в центральном отсеке обусловлено неспецифической оборонительной реакцией замирания, не соотнесенной с местом удара током. Выбор безопасного отсека связан с необходимостью запоминания места нанесения тока и выработкой пространственной дифференцировки между ним и опасным отсеком. На наш взгляд, анализу роли этих ассоциативных процессов может способствовать изучение эффектов нейротропных веществ, избирательно влияющих на обучение и память или страх.

Современная экспериментальная психофармакология располагает такими средствами. Препаратами, влияющими на обучение и память, служат ноотропы, обладающие широким спектром фармакологических эффектов [3]; к ним относятся, в частности, пирацетам и мексидол. Препаратами, влияющими на страх и тревогу, служат анксиолитики [4]. Важным механизмом их действия выступает модуляция ГАМК-ергической системы с помощью агонистов и антагонистов ГАМК-рецепторов в центральной нервной системе [5-9]. Широко известным агонистом ГАМК-рецепторов, используемым для влияния на страх, в том числе, при формировании УРПИ, является диазепам [10-12].

С учетом вышесказанного, в работе сопоставлено влияние пирацетама, мексидола и диазепама на УРПИ в установке из трёх отсеков с целью анализа формируемого при этом следа памяти.

\section{Материалы и методы}

Работа была выполнена на 83 самцах белых беспородных крыс массой 180-200 г. Крыс содержали в пластиковых клетках при 12-часовом световом дне и неограниченном доступе к воде и пище. Было проведено три серии опытов, в каждой из которых были контрольная и опытная группы (табл. 1). За 30 мин до эксперимента опытным животным первой серии внутрибрюшинно вводили 300 мг/кг пирацетама (125 мг/мл), второй $-0,5$ г/кг диазепама $(2,2$ мг/мл), третьей - 50 мг/кг мексидола (50 мг/мл). Контрольным животным в то же время вводили эквивалентный объем физиологического раствоpa.

Опыты проводили в камере размером $60 \times 30 \times 35$ см, разделенной на три отсека. Из освещенного центрального отсека дверцы вели в темные боковые, в одном из которых при выработке УРПИ крыса получала удар током (обозначенном в дальнейшем как "опасный отсек"), а в другом нет ("безопасный отсек"). В первой сессии в камере с открытыми дверцами в течение 3 мин оценивали спонтанную двигательную активность. Во второй сессии вырабатывали УРПИ, для чего животное помещали в освещенный отсек хвостом к дальней стенке и фиксировали ЛП захода в один из темных отсеков. Затем закрывали дверь и через электрифицированный пол наносили удар током (0,7 мА) длительностью 10 с. В 3-й сессии на следующий день крысу помещали в освещенный отсек и тестировали УРПИ. Если животное не покидало центральный отсек, его поведение регистрировали в течение 5 мин.

Все эксперименты проводили согласно "Принципам надлежащей лабораторной практики" (Национальный стандарт РФ ГОСТ Р 534342009) и положениям международной конвенции о "Правилах работы с экспериментальными животными" (European Communities Council Directives, November 24, 1986, 86/609/EEC).

Для оценки УРПИ помимо ЛП выхода из центрального освещенного отсека регистрировали выбор крысами одного из отсеков. Статистическую значимость увеличения ЛП при тестировании относительно исходной величины определяли с помощью парного критерия Вилкоксона; различие между опытной и контрольной группами - с помощью непарного критерия Вилкоксона; значимость частоты заходов в отсеки - с помощью критерия согласия частот [13].

\section{Результаты и обсуждение}

Экспериментальные данные, приведенные на рисунке, показывают, что удар током при переходе крысы из стартового отсека в один из темных при выработке УРПИ привел к многократному статистически значимому увеличению ЛП данной реакции при тестировании у контрольных животных в первых двух сериях 


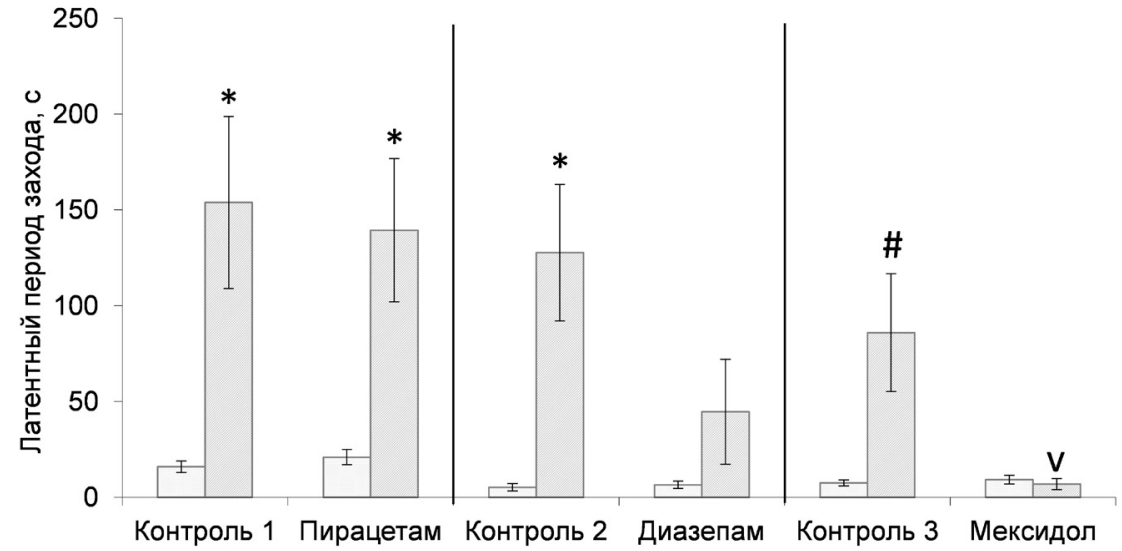

Рисунок. Латентные периоды выхода из центрального отсека.

Левые столбики в каждой паре - значение латентных периодов до обучения, правые - при тестировании.

* - значимое увеличение по сравнению с латентным периодом при обучении по парному критерию Вилкоксона $(\mathrm{p}<0,05)$; \# - тенденция к увеличению по сравнению с латентным периодом при обучении по парному критерию Вилкоксона $(\mathrm{p}<0,07) ; \mathrm{v}-$ значимое отличие от контрольной группы по критерию Вилкоксона $(\mathrm{p}<0,05)$

опытов. Это говорит о том, что с точки зрения общепринятого показателя успешной выработки УРПИ, каким является ЛП, обучение имеет место. Однако это не привело к предпочтению заходов животных в безопасный отсек (табл. 1). Число контрольных крыс, зашедших в безопасный отсек в первой серии, было в 4 раза меньше суммарного числа животных, оставшихся в центральном отсеке и зашедших в опасный отсек. В опытах второй серии число таких животных было даже меньше числа тех, которые выбрали значимым, что может указывать на отсутствие влияния препарата на обучение и память в этой модели. Однако, в отличие от ситуации с контрольными животными, число опытных крыс, зашедших в безопасный отсек, в разы превышало число зашедших в опасный отсек и оставшихся в центральном отсеке. Описанное отсутствие предпочтения безопасного отсека у контрольных животных и положительное влияние пирацетама на его выбор согласуются с ранее полученными данными [14], что говорит о хорошей воспроизводимости результатов опытов.

У контрольных животных третьей серии ЛП также резко увеличился (в 7 раз), хотя это увеличение не достигло статистически значимого уровня $(\mathrm{p}=0,056)$, что можно объяснить большим разбросом значений в данной группе за счет наличия необучившихся животных, ЛП у которых оставался низким. В противоположность описанному выше росту ЛП у контрольных и у подвергнутых влиянию пирацетама животных, у крыс под воздействием мексидола ЛП при тестировании, во-первых, не увеличился относительно исходного уровня и, во-вторых, был меньше той величины, которая была зарегистрирова-

Выбор животными отсека при тестировании условного рефлекса пассивного избегания

Таблииа 1

\begin{tabular}{|c|c|c|c|c|c|c|}
\hline Серия & Вещество & Опасный отсек & $\begin{array}{c}\text { Центральный } \\
\text { отсек }\end{array}$ & $\begin{array}{c}\text { Безопасный } \\
\text { отсек }\end{array}$ & $\mathbf{Z}$ & p* \\
\hline \multirow{2}{*}{1} & $\begin{array}{c}\text { Физраствор } \\
(n=10)\end{array}$ & 5 & 3 & 2 & 3,13 & 0,002 \\
\hline & $\begin{array}{c}\text { Пирацетам } \\
(\mathrm{n}=10)\end{array}$ & 1 & 2 & 7 & 2,236 & 0,025 \\
\hline \multirow{2}{*}{2} & $\begin{array}{c}\text { Физраствор } \\
(\mathrm{n}=20)\end{array}$ & 16 & 0 & 4 & 4,111 & $3,984 \mathrm{E}-5$ \\
\hline & $\begin{array}{c}\text { Диазепам } \\
(\mathrm{n}=20)\end{array}$ & 10 & 2 & 8 & 1,581 & 0,114 \\
\hline \multirow{2}{*}{3} & $\begin{array}{c}\text { Физраствор } \\
(n=16)\end{array}$ & 4 & 3 & 9 & 1,061 & 0,289 \\
\hline & $\begin{array}{l}\text { Мексидол } \\
(\mathrm{n}=7)\end{array}$ & 1 & 0 & 6 & 3,207 & 0,001 \\
\hline
\end{tabular}

* - величины критериев согласия частот и уровней значимости указаны относительно суммарной величины выбора опасного и центрального отсеков

только опасный отсек.

Различие в величинах ЛП в группе, получавшей инъекции пирацетама, и соответствующей контрольной группах не было статистически на у контрольных животных при тестировании УРПИ. В соответствии с общепринятыми представлениями, на основе этих результатов можно было бы заключить, что препарат не только не 
улучшает память, но, напротив, угнетает ее.

Однако, во-первых, это противоречит показанному ранее положительному влиянию мексидола на обучение и память [15]. Во-вторых, в данном опыте под воздействием мексидола более $85 \%$ крыс выбрали безопасный отсек, и ни одно опытное животное не осталось в центральном отсеке. Это свидетельствует о высокой эффективности мексидола в формировании следа памяти о месте нанесения болевого воздействия и упомянутого ранее "предвидения последствий захода в него". Короткий ЛП захода большинства крыс в безопасный отсек подчеркивает эффективное влияние препарата на пространственный компонент памяти в данной модели. Можно отметить, что мексидол обладает антиоксидантной активностью, которая может обеспечить выбор безопасного отсека, как это установлено в случае использования антиоксиданта карнозина [16].

Инъекция диазепама уменьшила величину ЛП ухода из центрального отсека по сравнению с ЛП у контрольных крыс. На этом основании считают, что этот агонист бензодиазепиновых рецепторов ухудшает память грызунов [11, 12]. Наши данные об отсутствии выбора безопасного отсека, приведенные в табл. 1, находятся в соответствии с этим выводом.

Из полученных результатов следует, что величины ЛП пассивного избегания и число заходов в безопасный отсек дают разнонаправленную характеристику формирования УРПИ. Это согласуется с ранее полученными результатами о том, что эти характеристики подчиняются различным количественным закономерностям [14]. Величины ЛП, характеризующие время замирания в центральном отсеке, в процитированной работе линейно зависели от силы тока и были больше всего при большем воздействии. Подобная линейная зависимость времени замирания от силы тока отмечена и другими авторами в модели посттравматического стрессового расстройства [17]. Предпочтение безопасного отсека, напротив, реже всего наблюдалось при большем воздействии, и при этом было больше всего животных, оставшихся в стартовом отсеке [14], что указывает на углубление замирания, затрудняющего выбор безопасного отсека. Следовательно, полученные данные подтверждают ранее высказанное предположение [2] о том, что процессы обучения, которые обусловливают задержку двигательной реакции и выбор безопасного отсека, имеют различную ассоциативную природу

Увеличение ЛП и соответствующего замирания после однократного обучения, свидетельствующее об угнетении врожденной реакции перехода грызунов из светлого отсека в темный, объясняется быстрым формированием условной эмоциональной реакции страха на основе классического обусловливания, что показано неоднократно в разных экспериментальных ситуациях [6-12, 17, 18]. Учитывая результаты опыта и данные литературы, нужно констатировать, что условнорефлекторный страх может быть увеличен с помощью усиления электроболевого воздействия и уменьшен с помощью анксиолитиков, что подтверждает его роль в формировании УРПИ.

Важно при этом отметить, что удар током при выработке УРПИ увеличивает замирание и ЛП двигательной реакции не только в той же установке, но и в челночной незатемненной камере, в которой этот удар не наносился, что свидетельствует о неспецифическом характере обусловленного страха [2]. Подобное увеличение замирания в одной камере вследствие электрокожного раздражения во второй наблюдалось и другими авторами, которые также придерживались мнения о неспецифической природе формируемого при этом условнорефлекторного страха [17, 19].

Как показывают результаты данного опыта и полученные ранее [2], быстрое формирование условной эмоциональной реакции страха, обеспечивающей резкое угнетение врожденного поведения, не приводит к быстрому формированию следа памяти, отражающему пространственные характеристики экспериментальной ситуации. Это, по-видимому, говорит о том, что запоминание места нанесения тока, пространственная дифференцировка, выбор безопасного отсека представляют собой более сложный процесс и более трудную задачу, чем формирование классического условного рефлекса.

На самом деле, необходимость выработки пространственной дифференцировки усложняет задачу, что используют для выявления нейрофармакологических воздействий на обучение и память [20, 21]. Показано, что изменение местоположения отверстия в челночной камере в ходе выработки реакции избегания резко нарушает ее воспроизведение. При этом ноотропы, не влияющие на выработку реакции избегания, способствовали усвоению пространственно видоизмененного навыка [21, 22]. На наш взгляд, именно указанное усложнение задачи, связанное с необходимостью определения безопасного отсека, объясняет, почему в нашем опыте пирацетам и мексидол, не увеличивая ЛП, отражающий выработку классической условной реакции страха, оказались более эффективными в предлагаемой модификации методики.

Наиболее интересным нам представляется 
Таблица 2

Влияние препаратов на величины латентного периода выхода из центрального отсека и выбор безопасного отсека

\begin{tabular}{|c|c|c|}
\hline \multirow{2}{*}{ Препарат } & \multicolumn{2}{|c|}{ Влияние препарата на: } \\
\cline { 2 - 3 } & ЛП & Выбор безопасного отсека \\
\hline Пирацетам & Отсутствует & Положительное \\
\hline Мексидол & Отрицательное & Положительное \\
\hline Диазепам & Отрицательное & Отсутствует \\
\hline
\end{tabular}

полученный в данной работе факт, ранее не отмеченный в известной нам литературе. Как сказано выше, увеличение ЛП обусловлено страхом, вызываемым током. Следовательно, отсутствие такого роста ЛП ухода из центрального отсека, наблюдаемое у крыс под воздействием мексидола, свидетельствует об отсутствии страха, несмотря на предыдущее воздействие тока. При этом ни одно животное не осталось в центральном отсеке, а 6 из 7 крыс зашли в безопасный отсек. Возможное объяснение этому основывается на двусторонних связях, которые существуют между способностью решить задачу и эмоциональным напряжением животных [23]. С этой точки зрения страх уменьшает способность решать задачу, а наличие информации, необходимой для решения задачи, уменьшает основу для возникновения страха. Мы показали ранее, что ноотропы, в том числе пирацетам и мексидол, помимо улучшения воспроизведения реакции избегания в условиях ее функционального нарушения, уменьшали и эмоциональное напряжение, выражающееся в межсигнальных реакциях, дефекации, уринации и других проявлениях $[15,21]$.

В наших опытах под воздействием мексидола быстро формируется след памяти, отражающий место нанесения тока, вследствие чего крысы не заходят в опасный, а выбирают безопасный отсек. В силу этого страх не увеличивается относительно исходной величины, и ЛП после удара током, в свою очередь, также не увеличивается, в отличие от того, что имеет место у контрольных животных.

Таким образом, полученные в работе результаты подтвердили ранее высказанное предположение [2] о различии ассоциативных процессов, вызывающих увеличение ЛП и выбор безопасного отсека. Торможение двигательной реакции, приводящее к увеличению ЛП ухода из центрального отсека, связано с образованием условной эмоциональной реакции страха, не соотнесенной с местом электрокожного раздражения. Выбор безопасного отсека обусловлен формированием пространственной памяти, обеспечивающей дифференцировку между опасным и безопасным отсеками. Для дальнейшего анализа роли этих ассоциативных процессов мы использовали препараты из класса ноотропов, предназначенных для стимуляции когнитивных и мнестических процессов, и анксиолитиков, уменьшающих тревогу и страх. В обобщенном виде полученные результаты о влиянии использованных препаратов на УРПИ представлены в табл. 2. Из полученных данных следует, что под воздействием ноотропов увеличивается предпочтение безопасного отсека, в то время как ЛП не увеличивается относительно контрольных величин. Анксиолитик диазепам, наоборот, уменьшил ЛП выхода из центрального отсека, но не повлиял на предпочтение. Эти дифференцированные фармакологические эффекты подтверждают, что УРПИ основан на формировании условной реакции страха, которая вызывает увеличение латентного периода ухода из центрального отсека, и памяти о месте электроболевого воздействия, которая обеспечивает выбор безопасного отсека.

Работа выполнена при финансовой поддержке госзадания «Нейробиологические основы поведения животных» (номер гостемы 11-116, номер ЦИТИС АААА-А16-116021660055-1).

Эксперименты проведены с соблюдением этических норм работы с животными, установленными Комиссией по биоэтике МГУ. Авторы заявляют, что у них нет конфликта интересов.

\section{СПИСОК ЛИТЕРАТУРЫ}

1. Bures J., Burešová O., Huston J. P. Techniques and basic experiments for the study of brain and behavior. N.Y.: Elsevier, 1976. 290 pp.

2. Inozemtsev A.N. Analysis of the memory trace

nature in passive avoidance response // Moscow Univ. Biol. Sci. Bull. 2013. Vol. 68. N 2. P. 53-57.

3. Malik R., Sangwan A., Saihgal R., Jindal D.P., Piplani P. Towards better brain management: 
nootropics // Curr. Med. Chem. 2007. Vol. 14. N 2. P. 123-131.

4. Castanheira L., Ferreira M.F., Sebastião A.M., Telles-Correia $D$. Anxiety assessment in pre-clinical tests and in clinical trials: a critical review // Curr. Top. Med. Chem. 2018. Vol. 18. N 19. P. 1656-1676.

5. Dubrovina N.I., Zinov'ev D.R. Contribution of GABA receptors to extinction of memory traces in normal conditions and in a depressionlike state // Neurosci. Behav. Physiol. 2008.Vol. 38. N 8. P. 775-779.

6. Pavlova I.V., Rysakova M.P. Effects of administration of an agonist and an antagonist of GABAA receptors into the basolateral nucleus of the amygdala on the expression and extinction of fear in rats with different freezing durations // Neurosci. Behav. Physiol. 2016. Vol. 46. N 2. P. 205-214.

7. Ehrlich I., Humeau Y., Grenier F., Ciocchi S., Herry $C$., Lüthi A. Amygdala inhibitory circuits and the control of fear memory // Neuron. 2009. Vol. 62. N 6. P. 757-771.

8. McEown K., Treit D. A2 GABAA receptor sub-units in the ventral hippocampus and $\alpha 5$ GABAA receptor sub-units in the dorsal hippocampus mediate anxiety and fear memory // Neuroscience. 2013. N 252. P. 169-177.

9. Smith K.S., Engin E., Meloni E.G., Rudolph $U$. Benzodiazepine-induced anxiolysis and reduction of conditioned fear are mediated by distinct GABAA receptor subtypes in mice // Neuropharmacology. 2012. Vol. 63. N 2. P. 250-258.

10. Kim D.H., Kim J.M., Park S.J., Lee S., Shin C.Y., Cheong J.H., Ryu J.H. Hippocampal extracellular signal-regulated kinase signaling has a role in passive avoidance memory retrieval induced by GABAA receptor modulation in mice // Neuropsychopharmacology. 2012. Vol. 37. N 5. P. 1234-1244.

11. Tsuji M., Takeda H., Matsumiya $T$. Modulation of passive avoidance in mice by the 5-HT1A receptor agonist flesinoxan: comparison with the benzodiazepine receptor agonist diazepam // Neuropsychopharmacology. 2003. Vol. 28. N 4. P. 664-674.

12. Vasudevan M., Parle M. Pharmacological evidence for the potential of Daucus carota in the management of cognitive dysfunctions // Biol. Pharm. Bull. 2006. Vol. 29. N 6. P. 1154-1161.

13. Кулаичев А.П. Методы и средства анали- за данных в среде Windows/STADIA. М.: НПО «Информатика и компьютеры», 1999. 241 с.

14. Иноземцев А.Н., Бельник А.П., Островская Р.У. Изучение условного рефлекса пассивного избегания в модифицированной трех камерной установке // Эксп. клин. фармакол. 2007. Т. 70. № 2. C. $67-69$.

15. Inozemtsev A.N. Biological origins of protective mechanisms activated by the disruption of higher nervous activity // Moscow Univ. Biol. Sci. Bull. 2009. Vol. 64. N 2. P. 57-62.

16. Berezhnoy D.S., Bokieva S.B., Stvolinskii S.L., Fedorova T.N., Inozemtsev A.N. Effect of carnosine on conditioned passive avoidance response in the norm and under hypoxia conditions // Moscow Univ. Biol. Sci. Bull. 2015. Vol. 70. N 3. P. 105-109.

17. Siegmund A., Wotjak C.T. A mouse model of posttraumatic stress disorder that distinguishes between conditioned and sensitised fear // J. Psychiatr. Res. 2007. Vol. 41. N 10. P. 848-860.

18. Konorski $J$. Integrative activity of the brain: An interdisciplinary approach. Chicago; London: Univ. Chicago Press, 1967. 531 pp.

19. Toropova K.A., Anokhin K.V. Modeling of post-traumatic stress disorder in mice: nonlinear relationship with the strength of the traumatic event // Neurosci. Behav. Physiol. 2019. Vol. 49. N 7. P. 875-886.

20. Stuchlík A., Petrásek T., Prokopová I., Holubová K., Hatalová H., Valeš K., Kubík S., Dockery C., Wesierska M. Place avoidance tasks as tools in the behavioral neuroscience of learning and memory // Physiol. Res. 2013. Vol. 62. N 1. P. 1-19.

21. Иноземиев А.Н., Капица И.Г., Гарибова Т.Л., Бокиева С.Б., Воронина Т.А. Сопоставление влияния ноотропов и анксиолитиков на функциональные нарушения реакции избегания // Вестн. Моск. ун-та. Сер. 16. Биология. 2004. № 3. C. 24-30.

22. Inozemtsev A.N., Agapitova A.E., Bokieva S.B., Glazova N.Yu, Levitskaya N.G., Kamenskii A.A., Myasoedov N.F. Differently directed influences of semax on the formation and functional impairments of an active avoidance reaction in rats // Neurosci. Behav. Physiol. 2015. Vol. 45. N 2. P. 173-178.

23. Simonov P.V. The emotional brain. physiology, neuroanatomy, psychology and emotion. N.Y.; London: Plenum Press, 1986. 267 pp.

Поступила в редакцию 27.06.2019 г.

После доработки 26.08.2019 г.

Принята в печать 02.09.2019 г. 


\title{
RESEARCH ARTICLE
}

\section{EFFECTS OF DIAZEPAM, PIRACETAM AND MEXIDOL ON PASSIVE AVOIDANCE RESPONSE}

\author{
A.N. Inozemtsev ${ }^{1, *}$, D.S. Berezhnoy ${ }^{1,2}$, A.V. Novoseletskaya ${ }^{1}$ \\ ${ }^{1}$ Department of Higher Nervous Activity, School of Biology, Lomonosov Moscow State University, \\ Leninskiye gory 1-12, Moscow, 119234, Russia; \\ ${ }^{2}$ Laboratory of Clinical and Experimental Neurochemistry, Scientific Center of Neurology, Volokolamsk \\ Highway 80, Moscow, 125367, Russia \\ "e-mail: a inozemtsev@mail.ru
}

\begin{abstract}
In experiments on rats, we compared the influence of anxiolytic diazepam and nootropics piracetam and mexidol on passive avoidance conditioning (PAC) in a three compartment apparatus that consisted of a light compartment, a dark dangerous compartment in which foot shock was delivered and a dark safe one where the rats were not punished. Electric foot shock during PAC caused a sharp increase in the latent period of the central compartment leaving during the testing in the control animals, but did not lead to the safe compartment choice. Based on these data on the differential impact of the foot shock on PAC, we formulated the assumption that learning processes, which determined the motor response delay and the safe compartment selection, had different associative nature. The increase in the latent period is associated with the classical fear conditioning regardless of the place of the current impact. The safe compartment choice, on the contrary, is associated with the memory trace formation about the location of the foot shock exposure. The use of pharmacological substances that affect fear and memory in different ways gave additional arguments in favor of the assumption of various associative processes that determined PAC. Reducing the level of fear with diazepam reduced the latent period of motor response relative to the control value, but did not affect the choice of a safe compartment. In contrast, the mnemotropic properties of piracetam and mexidol increased the preference for a safe compartment without increasing the latent period. These differential pharmacological effects confirm that PAC is based on the conditioned responses of fear, which causes an increase in latent period of leaving the central compartment, and on the memory of the electrical exposure location which provides the safe compartment choice.
\end{abstract}

Keywords: modified passive avoidance, memory, diazepam, piracetam, mexidol, conditioned fear, safe compartment choosing

\section{Сведения об авторах}

Иноземиев Анатолий Николаевич - докт. биол. наук, вед. науч. сотр. кафедры высшей нервной деятельности биологического факультета МГУ. Тел.: 8-495-939-50-01; e-mail: a_inozemtsev@mail.ru

Бережной Даниил Сергеевич - канд. биол. наук, науч. сотр. кафедры высшей нервной деятельности биологического факультета МГУ, науч. сотр. лаб. клинической и экспериментальной нейрохимии ФГБНУ «Научный центр неврологии». Тел.:8-495-939-50-01; e-mail: b@neurobiology.ru

Новоселецкая Анна Владимировна - канд. биол. наук, ст. науч. сотр. кафедры высшей нервной деятельности биологического факультета МГУ. Тел.:8-495-939-50-01; e-mail: neuron1211@rambler.ru 